\title{
An Analysis of The Actual Application of Middle School Textbooks in Respect to The Competencies in Mathematics
}

\author{
Soo-Cheol Kim1)
}

\begin{abstract}
In this paper, the researcher analyzes the middle-school-mathematics textbooks that were developed in accordance with the 2015 revision-curriculum, in Korea. Its aim is to provide implications for mathematics education by analyzing the actual application of the competencies in the mathematics textbooks. In order to accomplish this, the analysis of the textbooks was performed on: number \& operations; variables \& expressions; functions; geometry and probability \& statistics. The analytical criteria for judging whether or not such competencies are applied in the content of textbooks consists of the six mathematics competencies, presented by Ministry of Education[1]. Moreover, as the results of this study demonstrate problem-solving competency, communication competency and attitude \& practice competency were applied throughout the math textbooks well. However, the application rate of: the reasoning competency, creativity \& convergence competency and information processing competency were low.
\end{abstract}

Keywords : Analysis, Competency, Mathematics, Middle School, Textbook

\section{Introduction}

In the 2015 revision curriculum, the emphasis is placed on the development of creative and convergent talents with core competencies required by the knowledge and information society. In particular, the mathematics curriculum emphasizes the six core competencies such as problem solving, reasoning, communication, creativity \& convergence, information processing and attitude \& practice. Three competencies like problem solving, reasoning and communication were emphasized in the 2009 revision mathematics curriculum[2], which are mathematical processes already mentioned in the Principle and Standards for School Mathematics[3]. It is meaningful to look at how many the competencies are applied in mathematics textbooks according to the revised curriculum because many Korean teachers design and write lesson plans based on textbooks. The purpose of this study is to provide implications for teaching

Received(July 18, 2018), Review Result(1st: August 1, 2018, 2nd: August 29, 2018), Accepted(September 10, 2018)

1) (Professor) 38430 Dept. Mathematics Education, Daegu Catholic University, Hayang-Ro 13-13, Hayang-Eup, Gyeongsan-si, Gyeongsangbuk-do, Korea

email: sckim@cu.ac.kr 
methods in mathematics by analyzing the actual cases of the competencies shown in the revised middle-school-mathematics-textbooks.

\section{Study Method}

\subsection{Subject}

In this study, five textbooks[4-8] of the seventh-grade mathematics were analyzed. The textbooks were developed in accordance with the 2015 revision curriculum. Five textbooks were widely used in educational field and on-line materials were well developed also. The analysis of the textbooks was conducted on: number \& operations, variables \& expressions, functions, geometry and probability \& statistics. The below [Table 1] summarizes the common elements extracted from the textbook[4-8].

[Table 1] The Analyzed Units of Textbooks

\begin{tabular}{|c|c|c|}
\hline Part & Section & Subsection \\
\hline \multirow{4}{*}{$\begin{array}{l}\text { Number \& } \\
\text { operations }\end{array}$} & Fractional Decomposition & Fractional Decomposition \\
\hline & \multirow{3}{*}{ Integral and Rational Numbers } & Properties of Number Systems \\
\hline & & Addition and Subtraction \\
\hline & & Multiplication and Division \\
\hline \multirow{4}{*}{$\begin{array}{l}\text { Variables \& } \\
\text { expression }\end{array}$} & \multirow{2}{*}{ Variables and Expression } & Using Variables \\
\hline & & Calculating Linear Expression \\
\hline & \multirow{2}{*}{ Linear Equation } & Definition of Equation \\
\hline & & Linear Equation \\
\hline \multirow{4}{*}{ Functions } & \multirow{2}{*}{ Coordinate Planes and Graphs } & Ordered Pair and Coordinate \\
\hline & & Graphs \\
\hline & \multirow{2}{*}{$\begin{array}{c}\text { Direct Proportion and Reciprocal } \\
\text { Proportion }\end{array}$} & Direct Proportion \\
\hline & & Reciprocal Proportion \\
\hline \multirow{7}{*}{ Geometry } & \multirow{3}{*}{ Basic Figure } & Point, Line, Plane, Angle \\
\hline & & Position Relation \\
\hline & & Properties of Parallel Line \\
\hline & \multirow{2}{*}{ Construction and Congruent } & Constructing Triangle \\
\hline & & Congruence Condition of Triangle \\
\hline & \multirow{2}{*}{ Plane Figure } & Polygon \\
\hline & & Circle and Sector \\
\hline
\end{tabular}


Asia-pacific Journal of Convergent Research Interchange

Vol.4, No.3 September 30 (2018), pp. 73-81

http://dx.doi.org/10.14257/apjcri.2018.09.08

\begin{tabular}{|c|c|c|}
\hline & \multirow{5}{*}{ Solid figure } & Polyhedron \\
\hline & & Solid of Revolution \\
\hline & & Surface Area and Volume(Prism and Cylinder) \\
\hline & & Surface Area and Volume(Pyramid and Cone) \\
\hline & & Surface Area and Volume(Sphere) \\
\hline \multirow{4}{*}{$\begin{array}{c}\text { Probability \& } \\
\text { Statistic }\end{array}$} & \multirow{4}{*}{ Data analysis } & Stems and Leaves \\
\hline & & Frequency Distribution Table and Histogram \\
\hline & & Frequency Distribution Polygon \\
\hline & & Relative Frequency \\
\hline
\end{tabular}

\subsection{Procedure}

The researcher presented the analytical criteria of the math textbooks using the 2015 revision mathematics curriculum. The following [Table 2] shows that the analytical criteria for judging whether or not such competencies are reflected in the content of textbooks, focusing on the six mathematics competencies and their sub-factors[1].

[Table 2] An Analyzing Criteria of Mathematics Textbook

\begin{tabular}{|c|c|c|c|c|c|c|c|c|c|c|c|}
\hline \multirow{2}{*}{ Subsection } & \multirow{2}{*}{$\mathrm{P}$} & \multicolumn{2}{|c|}{$\mathrm{R}$} & \multicolumn{3}{|c|}{ C } & \multirow{2}{*}{$\mathrm{Cm}$} & \multicolumn{3}{|c|}{ I } & \multirow{2}{*}{ A } \\
\hline & & c & $\mathrm{j}$ & $\mathrm{cr}$ & $\mathrm{i}$ & $\mathrm{o}$ & & $\mathrm{d}$ & e & $\mathrm{t}$ & \\
\hline Fractional Decomposition & & & & & & & & & & & \\
\hline$\ldots$ & & & & & & & & & & & \\
\hline Relative Frequency & & & & & & & & & & & \\
\hline
\end{tabular}

P: Problem solving, R: Reasoning, C: Creativity \& Convergence, $\mathrm{Cm}$ : Communication, I: Information processing, A: Attitude \& Practice, c: conjecture, j: justification, cr: creativity, i: inner connection, o: outer connection, d: data analysis, e: engineering, t: tools for math education

Using the above analytic criteria, the researchers requested three mathematics teachers with more than 10 years of experience to analyze each of the five mathematics textbooks[4-8], and they were marked as ' 1 ' if they showed the competence and 'blank' if they did not. The researchers confirmed the agreement of the analyzed data, and tried to secure the validity of the inconsistent parts through a specialist council composed of one professor of mathematics 
education and three mathematics teachers. The below [Table 3] is a part of the analysis of textbook[5].

[Table 3] An Examples of Analysis

\begin{tabular}{|c|c|c|c|c|c|c|c|c|c|c|c|}
\hline \multirow[b]{2}{*}{ Subsection } & \multirow{2}{*}{$\mathrm{P}$} & \multicolumn{2}{|c|}{$\mathrm{R}$} & \multicolumn{3}{|c|}{ C } & \multirow{2}{*}{$\mathrm{Cm}$} & \multicolumn{3}{|c|}{ I } & \multirow{2}{*}{ A } \\
\hline & & c & $\mathrm{j}$ & $\mathrm{cr}$ & $\mathrm{i}$ & $\mathrm{o}$ & & $\mathrm{d}$ & $\mathrm{e}$ & $\mathrm{t}$ & \\
\hline Fractional Decomposition & 1 & 1 & 1 & & & 1 & 1 & 1 & & 1 & 1 \\
\hline $\begin{array}{c}\text { Properties of Number } \\
\text { Systems }\end{array}$ & 1 & 1 & & & & & 1 & & & & 1 \\
\hline$\ldots$ & & & & & & & & & & & \\
\hline Relative Frequency & 1 & & & & & 1 & 1 & 1 & & & 1 \\
\hline
\end{tabular}

\section{Result}

\subsection{The Application Rate of The Competencies in Math Textbooks}

Problem-solving competency was reflected well throughout the math textbooks such as number \& operations, variables \& expressions, functions, geometry and probability \& statistics. The application rate of communication competency and attitude \& practice competency were generally high. However, the application rate of reasoning competency, creativity \& convergence competency(except outer connection) and information processing competency were low. In the textbook B, the rate of 'justification $(7.1 \%)^{\prime}$ which is the sub-factor of reasoning competency was quite low. In the textbook[6], the rate of 'conjecture(10.7\%)' which is the sub-factor of reasoning competency was very low. In the creativity \& convergence competency, the rate of 'creativity and inner connection' was low. Looking closely, the application rate of 'creativity' in the textbook[4], textbook[5] and textbook[8] were each 25\%. The application rate of 'inner connection' in the textbook B was 21.4\%. Textbook[5] and textbook[6] were each 25\%. The application rate of the sub-factors included in the information processing competency was low. Looking detail, the application rate of 'data analysis' in the textbook[4] and textbook[5] were each $21.4 \%, 17.9 \%$. The application rate of 'engineering' in the textbook[4] was $25 \%$. The rate of 'tools for math education' in the textbook[4] and textbook[8] are each 14.3\%, $21.4 \%$. 
As a result of analyzing the seventh grade mathematics textbooks according to the revised curriculum, the actual application rate $(\%)$ of the competencies of the five mathematics textbooks is as shown in the following table.

[Table 4] The Result of Analysis

unit $(\%)$

\begin{tabular}{|c|c|c|c|c|c|c|c|c|c|c|c|}
\hline \multirow{2}{*}{ Competencies } & \multirow[b]{2}{*}{$\mathrm{P}$} & \multicolumn{2}{|c|}{$\mathrm{R}$} & \multicolumn{3}{|c|}{$\mathrm{C}$} & \multirow[b]{2}{*}{$\mathrm{Cm}$} & \multicolumn{3}{|c|}{ I } & \multirow[b]{2}{*}{ A } \\
\hline & & c & $\mathrm{j}$ & $\mathrm{cr}$ & $\mathrm{i}$ & $\mathrm{o}$ & & d & e & $t$ & \\
\hline [4] & 100 & 35.7 & 7.1 & 25.0 & 21.4 & 64.3 & 92.9 & 21.4 & 35.7 & 14.3 & 92.9 \\
\hline [5] & 100 & 60.7 & 50.0 & 25.0 & 25.0 & 82.1 & 92.9 & 17.9 & 25.0 & 28.6 & 92.9 \\
\hline [6] & 100 & 10.7 & 28.6 & 39.3 & 25.0 & 92.9 & 92.9 & 28.6 & 32.1 & 28.6 & 92.9 \\
\hline [7] & 100 & 35.7 & 57.1 & 46.4 & 35.7 & 71.4 & 92.9 & 28.6 & 32.1 & 42.9 & 92.9 \\
\hline [8] & 100 & 32.1 & 32.1 & 25.0 & 32.1 & 78.6 & 85.7 & 28.6 & 39.3 & 21.4 & 89.3 \\
\hline Average & 100 & 35 & 35 & 32.1 & 27.8 & 77.9 & 91.5 & 25 & 32.8 & 27.2 & 92.2 \\
\hline
\end{tabular}

\subsection{The Actual Application Cases of The Competencies in Math Textbooks}

The qualitative analysis of the actual application of competencies in the revised math textbooks can provide an objective basis for the quantitative analysis. In addition, providing examples of how the competencies is reflected in math textbook contents can provide guidance for mathematics teachers to design their lessons that take the competencies into account.

The following [Fig. 1] is shown that the example of problem solving competency, reasoning competency(conjecture, justification), communication competency, information processing competency(data analysis) and attitude \& practice competency.

The below [Fig. 2] shows the process of solving the 'surface area of the prism' of a solid figure unit in the middle school geometry with algebraic methods using real life materials. It is shown that the example of problem solving competency, reasoning competency(conjecture), communication competency, creativity \& convergence(inner connection, outer connection) and attitude \& practice competency. 
수학 격랑 기르기

운제를 하렬하고 설명 할 때는

운제의 조건과 징노틀 막악하고 출이 진락을 생 긱하다.

지신의 상긱을 명혁하

게 잔담한다.
다옴은 어느 모임의 구성원의 나이를 글로 나타낸 것이다. 구성원의 나이를 두 가지 이상 의 방법으로 구하고 자신의 풀이 방법을 설명하시오.

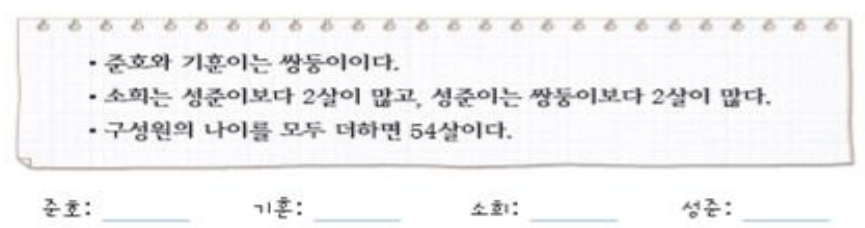

When describing and solving a problem.

$\checkmark$ Identify the conditions and information of the problem and think about the solution strategy.

$\sqrt{ }$ Communicate Self-thought clearly

The following is the age of members of a group. Find the age of the member in more than one way and describe your work.

- Junho and Kihun are twins.

- Sohee is two years older than Sung Jun. Sung Jun is two years older than twins.

- The sum of the menbers age is 54 years old.

[Fig. 1] The Example of Problem Solving Competency, Reasoning Competency(Conjecture, Justification), Communication Competency, Information Processing Competency(Data Analysis) and Attitude \& Practice Competency([7], pp.87)

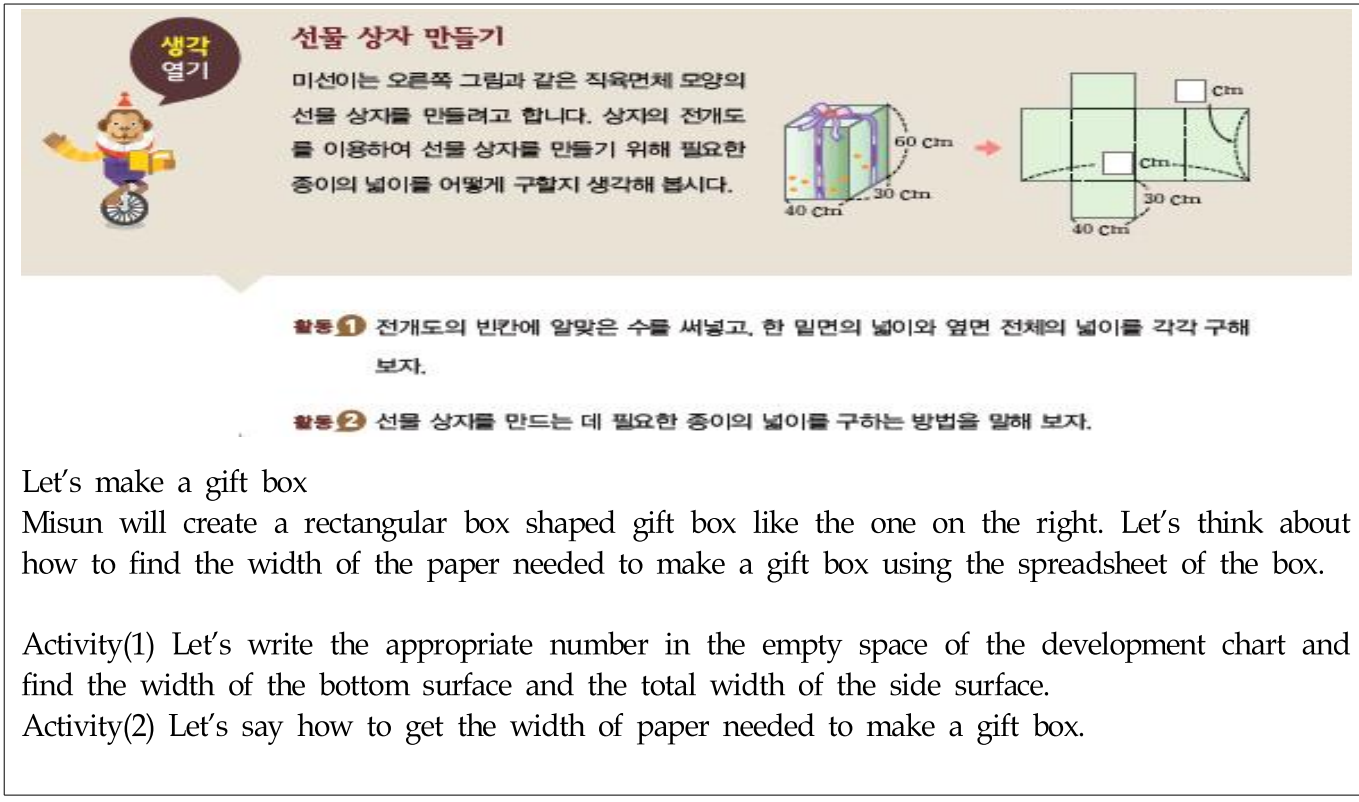

[Fig. 2] The Example of Problem Solving Competency, Reasoning Competency(Conjecture),

Communication Competency, Creativity \& Convergence(Inner Connection, Outer Connection) and Attitude \& Practice Competency([5], pp.223) 
The following [Fig. 3] shows the process of representing graph with the 'relation of direct proportion and reciprocal proportion' of a function part. It is shown that example of problem solving competency, information processing competency(engineering) and attitude \& practice competency.

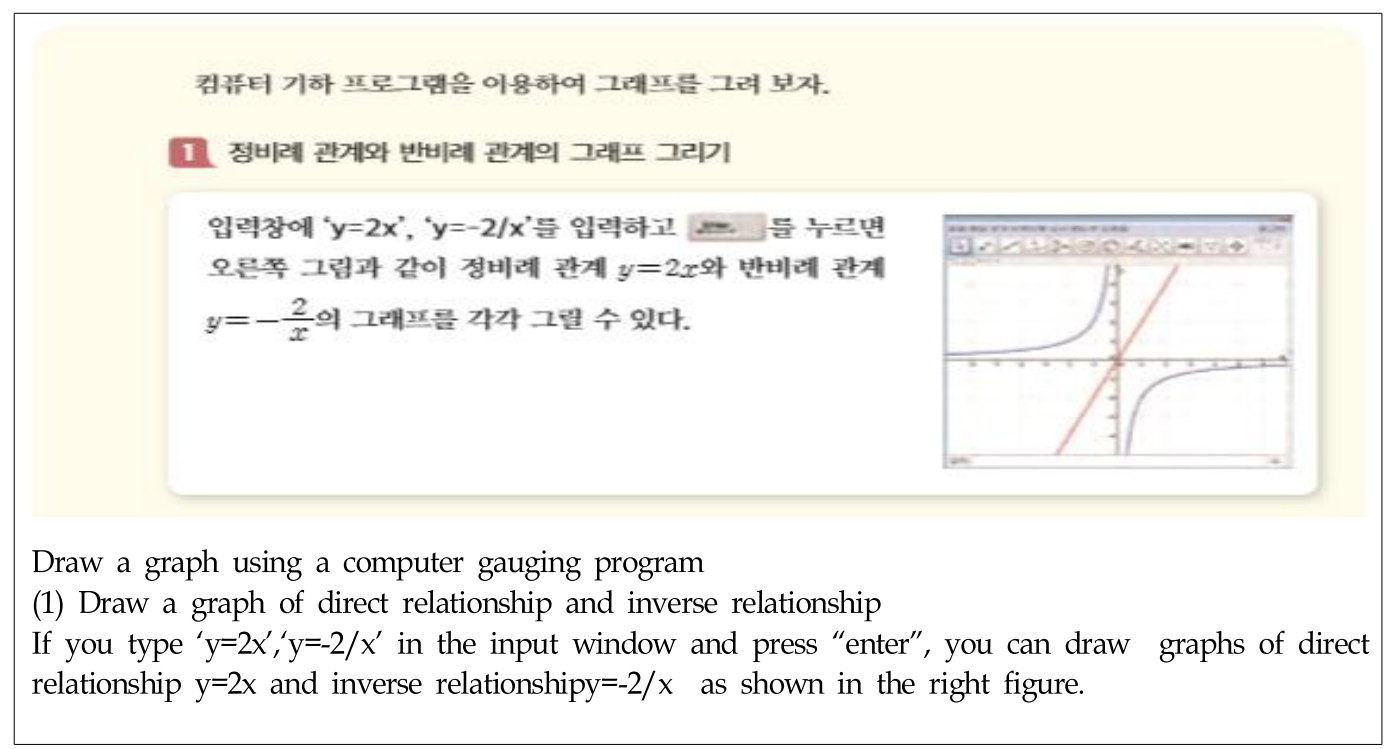

[Fig. 3] The Example of Problem Solving Competency, Information Processing Competency(Engineering) and Attitude \& Practice Competency([4], pp.137)

The below [Fig. 4] is shown that the example of problem solving competency, reasoning competency(conjecture, justification), communication competency, information processing competency(tools for math education) and attitude \& practice competency.

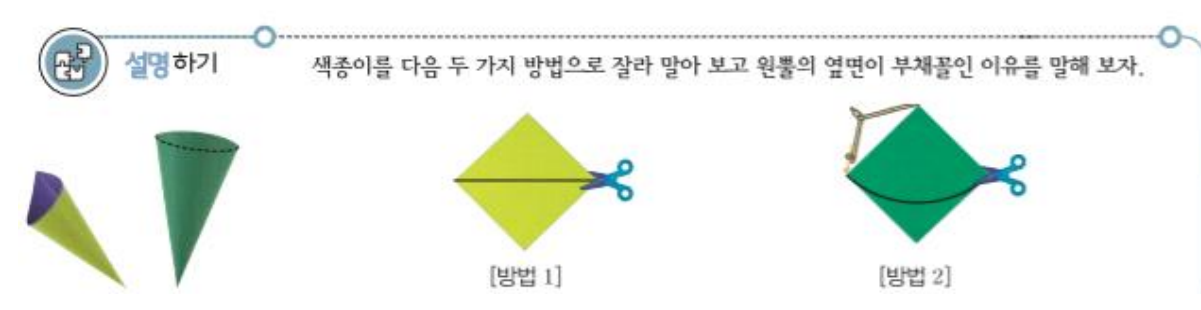

Explanation

Cut the colored paper in two ways and tell why the sides of the cone are fan-shaped.

[Fig. 4] The Example of Problem Solving Competency, Reasoning Competency(Conjecture, Justification), Communication Competency, Information Processing Competency(Tools for Math Education) and Attitude \& Practice Competency([6], pp.236) 
The following [Fig. 5] shows the process of representing an expression 'using variables' of a variables \& expression unit in the middle school algebra using real context. It is shown that the example of problem solving competency, reasoning competency(justification), communication competency, creativity \& convergence(creativity, outer connection) and attitude \& practice competency.

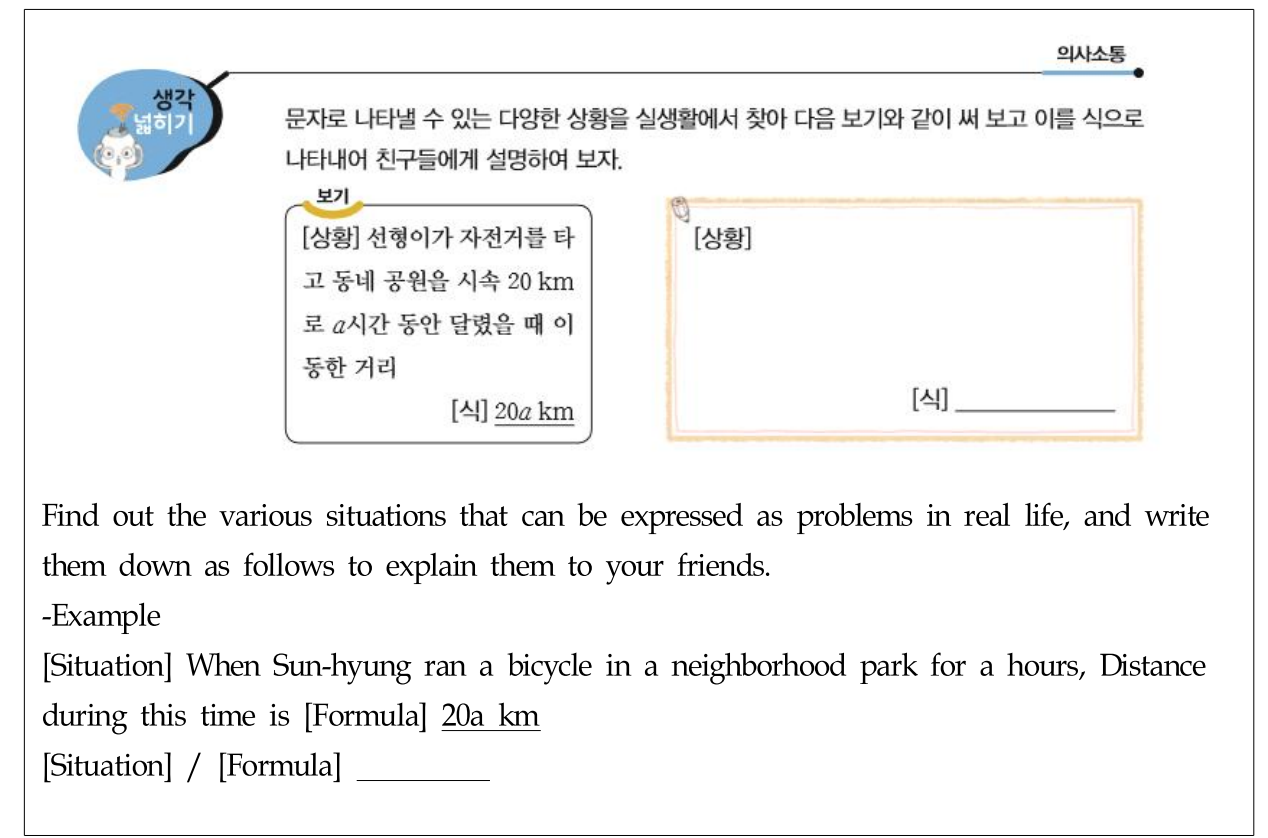

[Fig. 5] The Example of Problem Solving Competency, Reasoning

Competency(Justification), Communication Competency, Creativity \& Convergence

(Creativity, Outer Connection) and Attitude \& Practice Competency([8], pp.78)

\section{Conclusion and Suggestions}

In the mathematics textbooks according to the 2015 revision curriculum, problem-solving competency, communication competency and attitude \& practice competency were applied to all areas such as number \& operations, variables \& expressions, functions, geometry, and probability \& statistics. On the other hand, the application rate of reasoning competency and information processing competency were relatively low. In the case of creativity \& convergence competency, the application rate of 'outer connection' factor was high, but the rate of 'inner connection' factor and 'creativity' factor was low.

Therefore, the curriculum or textbook developers should fully consider the factors for expanding reasoning competency, creativity \& convergence competency and information 
processing competency in middle school mathematics curriculum.

As the results of the analysis, only one of the five textbooks was well reflected in the 'conjecture' factor, and two of the five textbooks were well reflected in the 'justification' factor. Three of the five textbooks were less than $25 \%$ in the 'creativity' factor, and only one of the five textbooks was more than $35 \%$ in the 'inner connection' factor. Within the information processing competency, the application rate of 'data analysis' and 'tools for math education' factors were low.

Teachers need to be aware of the following when designing a class that takes core competencies into account in mathematics. First, it is necessary to utilize 'conjecturing' and 'justifying' in the classroom so that students can expand their reasoning competency. Second, creativity \& convergence competency can be enhanced by presenting 'real life problems' or 'open-ended problems' to students. Third, in order to enhance the information processing competency of students, it is needed to collect data from 'social phenomena' or 'real life materials', to organize and interpret them, and to use various 'educational tools' when 'justifying'.

\section{Acknowledgement}

This work was supported by research grants from Daegu Catholic University in 2017.

\section{References}

[1] Ministry of Education, Mathematics curriculum, Ministry of Education, Korea, (2015)

[2] Ministry of Education and Science Technology, Mathematics curriculum, Ministry of Education and Science Technology, Korea, (2009)

[3] National Council of Teachers of Mathematics, Principles and standards for school mathematics, National Council of Teachers of Mathematics, USA, (2000)

[4] Hwang, S. W., Middle School Mathematics 1, Mirae-N, Korea, (2018)

[5] Kang, O. K., Middle School Mathematics 1, Dongaculpan, Korea, (2018)

[6] Kim, H. K., Middle School Mathematics 1, Joeunchaek-Sinsago, Korea, (2018)

[7] Kim, W. K., Middle School Mathematics 1, Bisangkyoyuk, Korea, (2018)

[8] Ryu, H. C., Middle School Mathematics 1, Cheonjaekyoyuk, Korea, (2018) 